\title{
Construcción de un poder nacional durante la Confederación rosista. La concentración de potestades eclesiásticas en la figura del Encargado de Relaciones Exteriores: Argentina 1837-1852/
}

\author{
Building of National Government during Rosas’ \\ Confederation: The Foreign Affairs Office \\ and the Centralization of Ecclesiastical Authority \\ in Argentina. 1837-1852
}

Ignacio Martínez

Universidad Nacional de Rosario, CONICET, Rosario, Argentina

Este artículo analiza los medios utilizados por Juan Manuel de Rosas para gravitar crecientemente en las iglesias de la Confederación argentina. Relaciona ese avance con la construcción de un gobierno nacional e identifica las variables que lo hicieron posible: primero, la incapacidad de las provincias para asegurar el funcionamiento de las estructuras eclesiásticas, segundo, la coincidencia coyuntural de intereses entre Roma y Rosas para concentrar la autoridad sobre las iglesias argentinas.

Palabras Clave: Argentina; Iglesia Católica; Confederación; Santa Sede; Juan Manuel de Rosas.

This paper studies the means by which Juan Manuel de Rosas controlled the churches of Argentinean Confederation. Rosas' increasing ecclesiastical control was linked with the building of a national authority. The factors that made it possible are also taken into account: firstly, provincial incapability to run local churches; secondly, momentary coincidence between the Holy See and Rosas in their aim of centralizing ecclesiastical power.

Keywords: Argentina; Catholic Church; Confederation; Holy See; Juan Manuel de Rosas. 


\section{Introducción}

Una de las características salientes de la historia política de la primera mitad del siglo XIX en el Río de la Plata fue la imposibilidad de dictar un texto constitucional que rigiera en todo el territorio. Luego de la caída en 1820 del gobierno central en Buenos Aires — que había intentado durante diez años conservar bajo su mando la jurisdicción del virreinato del Río de la Plata-, el problema de la constitución se agudizó. Es que sancionar una carta magna implicaba a partir de entonces la construcción desde sus cimientos de una autoridad que gobernara por sobre los diferentes estados provinciales, que se habían declarado autónomos y soberanos entre 1815 y 1820.

La comprensión de ese periodo avanzó un gran paso cuando sus historiadores se desprendieron del supuesto de que el proceso revolucionario había sido conducido por el impulso irrefrenable de independencia de una nación que encarnaba valores republicanos, enfrentados a los del régimen monárquico. Por el contrario, está claro hoy que fue en los ámbitos provinciales donde las instituciones y prácticas republicanas se pusieron a prueba y que estos primeros ensayos no necesitaron de una constitución o de un estado, ambos nacionales, sino que les bastó con adoptar una organización confederal para relacionarse entre sí. ${ }^{1}$ El reconocimiento, por parte de los investigadores, de la lógica confederal de la primera mitad del siglo XIX fue reflejada en una «federalización» de los estudios históricos, que se abocaron a analizar en cada realidad local los procesos de disolución de las formas políticas de Antiguo Régimen y la experimentación de nuevas instituciones y prácticas para legitimar y ejercer el poder.

Lamentablemente, este viraje fructífero no fue acompañado por un desarrollo similar de investigaciones sobre las lógicas de construcción política que se vivieron a escala supraprovincial, particularmente a partir de la década de 1830 y hasta mediados de siglo XIX. Durante ese periodo, Juan Manuel de Rosas no sólo consolidó su poder como gobernador de la provincia de Buenos Aires, sino que también subordinó las demás provincias

1 El punto de partida de esta concepción son los trabajos de José Carlos Chiaramonte, que llamaron la atención sobre el carácter confederal (y no federal) de la organización política rioplatense entre 1820 y 1853 . La argumentación de Chiaramonte articula variables como la persistencia del derecho natural y de gentes como norma para regular la relación entre las provincias, la debilidad de una identidad nacional frente a la identidad local o americana, la inexistencia de una clase social dominante y de un Estado nacional hasta la caída de Rosas. Todas estas ideas están expuestas en Chiaramonte, 1991, 1993 y 1997. 
a su liderazgo. Se han destacado como factores de esa gravitación el poderío económico de la provincia de Buenos Aires, una hábil utilización del pacto federal que suscribieron todas las provincias entre $1831 \mathrm{y} 1832$, y el manejo de las Relaciones Exteriores que delegaron en Rosas los gobiernos provinciales. ${ }^{2}$ Sin embargo, son muy escasos los estudios que reflexionaron sobre el modo en que estas variables generaron una forma de gobierno supraprovincial con cierta lógica y algún nivel de estabilidad. ${ }^{3}$ Por fortuna, en los últimos años se han multiplicado los estudios que, si bien no abordan de lleno el problema de la construcción de poderes con ese alcance más allá de lo provincial, analizan el desarrollo de identidades políticas y redes intelectuales que trascendieron ese ámbito, colaborando en la formación de un espacio político más amplio. ${ }^{4}$

Este artículo comparte con los trabajos recién citados el interés por las formas de construcción de un espacio político supraprovincial. Específicamente, estudia la política eclesiástica asumida por Rosas frente a las autoridades locales (tanto civiles como religiosas) durante el periodo de su consolidación como líder de la Confederación argentina. Se intentará demostrar que las facultades que Rosas adquirió gradualmente sobre el ámbito eclesiástico colaboraron en la construcción de un poder supraprovincial —que los funcionarios rosistas denominaban «nacional»—, partiendo de la debilidad jurisdiccional de las provincias en esta materia. Antes de seguir, quizás valga la pena aclarar el alcance de esta hipótesis. Al analizar las formas en que Rosas ejerció ese poder por encima de lo provincial no se pretende proponer la existencia de un estado nacional, en potencia o en acto. A este respecto se tiene en cuenta la advertencia de José Carlos Chiaramonte sobre el riesgo de interpretar la creciente gravitación política de la provincia de Buenos Aires como un proceso de organización estatal. ${ }^{5}$ Pero este artículo sí se propone demostrar que, hacia el fin de su

2 Tulio Halperin Donghi integra la variable económica con un complejo análisis político de la situación argentina durante el Rosismo en Halperín Donghi, 1972. José Carlos Chiaramonte encuentra en la fuerte gravitación económica del puerto de Buenos Aires el origen de las fuerzas centrípetas que mantienen una mínima unidad entre las provincias sometidas a fuerzas centrífugas igualmente poderosas de origen económico pero sobre todo social, al no existir una clase dominante nacional que termine de consolidar un gobierno también nacional. Véase Chiaramonte, 1991.

3 La excepción es el muy sugerente libro de Tau Anzoátegui, 1996, que analiza la manera en que se fue creando un poder nacional (que el autor llama Estado Federal) a partir de las bases legales otorgadas por el Pacto Federal de 1831 y la delegación de las Relaciones Exteriores en la persona de Rosas.

4 Myers, 1998, 1999; García de Saltor, 2003; Mata y Bragoni, 2007.

5 Chiaramonte, 1993, 122-124. 
mandato, Rosas fue más allá de su rol como árbitro entre estados soberanos y autónomos. ${ }^{6}$ La segunda hipótesis es que la concentración de facultades de gobierno eclesiástico en manos de Rosas se legitimó inicialmente con los mismos argumentos con que se defendía la autoridad papal. Finalmente, se exploran los límites de esa concentración. Por un lado, se propone que la defensa rosista de la organización confederal obstaculizó la cristalización completa de mecanismos de gobierno eclesiástico a escala nacional y, por el otro, que, al abandonar la defensa de la primacía romana, Rosas encontró un nuevo tipo de resistencia a la concentración de poder que no surgía de las provincias, sino de autoridades eclesiásticas imbuidas de una concepción de la Iglesia organizada en torno al poder pontificio.

\section{El problema del gobierno eclesiástico después de 1810}

La revolución de mayo de 1810 en Buenos Aires colocó a la capital del virreinato del Río de la Plata y a toda su porción central y meridional fuera de la jurisdicción de las autoridades peninsulares. A partir de allí, el territorio rebelde vivió un periodo turbulento que sacudió las estructuras tradicionales de gobierno a causa de dos fenómenos disparados por la revolución: el de las guerras de independencia y el de la permanente provisionalidad del poder revolucionario, que durante diez años no consiguió fijar criterios de legitimidad política aceptados por todos los actores políticos de la región. El problema fundamental consistió en encontrar una fórmula consensuada para expresar la nueva soberanía de base popular que la revolución había traído consigo. ${ }^{7}$

Como consecuencia de la revolución, las iglesias rioplatenses quedaron incomunicadas con las autoridades residentes en territorio leal al gobierno español. El espacio que se vio afectado por esta incomunicación comprendía a las diócesis de Córdoba (que incluía la región de Cuyo y las ciudades de La Rioja y Córdoba, con sus respectivas jurisdicciones), Buenos Aires (abarcaba a la Mesopotamia argentina, la Banda Oriental del Uruguay, la jurisdicción de Santa Fe y la de Buenos Aires) y Salta, creada

6 Aquí se plantea una diferencia con Chiaramonte, quien afirma que las funciones de Rosas en la Confederación se mantuvieron dentro de los límites que le imponían sus potestades como encargado de Relaciones Exteriores, jefe de los ejércitos federales y «árbitro y mediador oficioso en diferendos interprovinciales...» (Chiaramonte, 1993, 122-124).

7 Chiaramonte, 1997; Goldman, 1998; Ternavasio, 2009. 
en 1806 a partir de un desgajamiento de la diócesis cordobesa, con jurisdicción sobre las futuras provincias de Santiago del Estero, Catamarca, Tucumán, Salta y Jujuy. Estos obispados perdieron el contacto con la sede arzobispal de Charcas y las órdenes religiosas lo hicieron con sus superiores generales en la Península. La situación se agravó con el correr de los años. Entre 1812 y 1819 las tres diócesis quedaron desprovistas de sus obispos y nombrar nuevos era casi imposible porque el papa no reconocía a los movimientos insurgentes en Hispanoamérica y se negaba a expedir las imprescindibles bulas de institución episcopal para los candidatos de los gobiernos independentistas. Para empeorar aún más el panorama, en 1820, al desaparecer el poder central encarnado en el Directorio, lo hizo también la autoridad que había intentado heredar el derecho de patronato que detentaba el rey sobre esos obispados. El denominado regio patronato indiano era la facultad que poseía el monarca para nombrar a las personas que ocuparían los beneficios eclesiásticos dentro de sus territorios americanos, desde los arzobispos a los párrocos, y que incluía también la obligación de fundar, erigir y dotar a los templos. En torno a la figura del patronato se aglutinaban una serie de potestades del poder civil sobre el espacio eclesiástico que eran parte esencial de la soberanía de la corona española en América. Una de las más importantes fue la capacidad de otorgar o negar el pase regio o exequatur a las disposiciones papales, requisito indispensable para que la normativa pontificia tuviera vigor en los reinos españoles. ${ }^{8}$ Todo este vasto conglomerado de facultades era ejercido siguiendo la lógica piramidal de la monarquía hispana: mientras el rey, asesorado por el Consejo de Indias, poseía la potestad de presentar a los obispos y canonjías al papa, delegaba en los vice-patronos (siempre los virreyes, luego, y no sin disputa, los gobernadores-intendentes) la atribución de presentar a quienes ocuparían los demás beneficios en cada diócesis. ${ }^{9}$

Las autoridades provinciales que surgieron en la década de 1820 como únicos poderes soberanos buscaron ocupar el lugar del patrono, pero encontraron más dificultades aún que el extinto Directorio para hacerlo, porque la convivencia de varias provincias en una misma diócesis ocasionó conflictos, particularmente cuando aquellas que no alojaban a la sede diocesana debían aceptar que sus sacerdotes recibieran órdenes de las autoridades eclesiásticas residentes en provincias vecinas. El problema era de

8 Recomiendo dos obras para entender la importancia del patronato en la monarquía española: Di Stefano y Zanatta, 2000 y Hermann, 1988.

9 Lida, 2006, 125-128. 
primer orden, porque el control de las estructuras eclesiásticas se consideraba todavía un componente fundamental de la soberanía y, por lo tanto, no permitía la injerencia de poderes extraños, menos aún de vecinos que siempre miraban con buenos ojos la posibilidad de subordinar a los gobiernos colindantes. Frente a esta situación se disparó entre las provincias una carrera por conseguir la diócesis propia que desencadenó varias disputas jurisdiccionales. Las autoridades políticas provinciales $-\mathrm{y}$ también las eclesiásticas - debieron acudir constantemente a instancias supraprovinciales para dirimir esos conflictos.

Desde la visita de la misión pontificia encabezada por Giovanni Muzi durante los años 1823 y 1824, la Santa Sede comenzó a intervenir como autoridad superior en materia eclesiástica. ${ }^{10}$ Sin embargo, las intervenciones de Roma sobre esas lejanas y sumamente inestables iglesias rioplatenses recrudecieron muchas veces los conflictos en lugar de aplacarlos. La curia romana contaba con escasa información para tomar decisiones: la misión Muzi había recorrido sólo unas pocas provincias y lo había hecho de manera fugaz, del resto le llegaban noticias sesgadas, remitidas por gobiernos provinciales (o por sus comisionados) empeñados en conseguir su autonomía eclesiástica. Orientado por fuentes tan tendenciosas, el papa nombró autoridades con escasas capacidades para ejercer el cargo otorgado, o creó nuevas jurisdicciones que eran económica e institucionalmente inviables. Los ejemplos de malas decisiones tomadas por la Santa Sede sobran: la creación de la diócesis de Cuyo, con sede en San Juan, generó larguísimos conflictos con la vecina provincia de Mendoza - también incluida en el obispado y de mayor importancia que la nueva sede- y con las autoridades de la diócesis de Córdoba - que perdía una porción importante de su territorio al ser creado el nuevo obispado-; el intento de nombrar en la diócesis cuyana un obispo auxiliar, con sede en San Luis, no fue menos inoportuno, como veremos más adelante.

Para la flamante República Oriental del Uruguay, el papa nombró en 1830 un vicario apostólico, Pedro Alcántara Giménez, que fue rechazado por el gobierno uruguayo por ser español peninsular. El obispo chileno José Ignacio Cienfuegos, que había gestionado en Roma el envío de la misión Muzi, explicaba a Benito Lascano en 1830 que «En Roma no tienen conocimiento topográfico de la América y división de provincias», como así tampoco de las autoridades políticas y eclesiásticas de las provincias argen-

10 Ayrolo, 1996. 
tinas. ${ }^{11}$ Frente a estas dificultades se ensayaron al menos dos soluciones. En primer lugar, desde las oficinas pontificias se destacó un nuncio en Río de Janeiro con incumbencia en los asuntos eclesiásticos de toda la América austral. Allí debían confluir los informes de una creciente red de eclesiásticos confiables distribuidos por todo el territorio. El obispo Mariano Escalada, quien auxiliaba al anciano Mariano Medrano en la diócesis de Buenos Aires, era el centro de esa trama para las iglesias rioplatenses. Los informantes leales debían ofrecer al papa un panorama menos difuso que le permitiera tomar decisiones sobre terreno firme. ${ }^{12}$

La segunda solución no surgió del ámbito eclesiástico, sino del civil, cuando Juan Manuel de Rosas se constituyó en árbitro de las disputas entre las autoridades locales utilizando y ampliando las atribuciones que le otorgaba el encargo de las relaciones exteriores. En las páginas que siguen nos concentraremos en esta segunda salida para estudiar cómo, sobre esa figura, se fue construyendo una autoridad supraprovincial en materia eclesiástica.

\section{Atribuciones en materia eclesiástica para el encargado de Relaciones Exteriores: el decreto de 1837}

La figura de encargado de Relaciones Exteriores como autoridad supraprovincial existía en las provincias rioplatenses antes de la llegada de Rosas al poder. Desde la caída del Directorio en 1820, el gobierno de Buenos Aires había asumido de hecho el manejo de las relaciones exteriores en nombre de las demás provincias y esta situación se había prolongado hasta la reunión del congreso constituyente de 1824-27. La «Ley fundamental», sancionada por el congreso en enero de 1825, refrendó formalmente el manejo de las relaciones exteriores en manos del gobierno de Buenos Aires hasta la institución del poder ejecutivo nacional. En febrero de 1826 fue sancionada la ley de presidencia y, a partir de ese momen-

11 José Ignacio Cienfuegos a José I. de Castro Barros, Santiago de Chile, 25 de octubre de 1830, Archivio Segreto Vaticano, Archivio Nunziatura Brasile (en adelante ASV, Arch. Nunz. Brasile.), 265, 131-131v. La monumental obra de Bruno, 1966-1976, pasa revista a todos los conflictos que se desencadenaron tras estas disposiciones. Roberto Di Stefano identificó tempranamente el peso de la organización confederal en estos conflictos: Di Stefano y Zanatta, 2000.

12 Basta una rápida recorrida por los fondos del Archivo de la Nunciatura en Río de Janeiro para advertir la importancia que revisten estos informes en la correspondencia de los delegados pontificios. Véase ASV, Arch. Nunz. Brasile, 264, 265, 268, 271, 272 y 274. 
to, el ejecutivo nacional estuvo a cargo de los negocios exteriores. Caído el poder central en agosto de 1827, las provincias delegaron en el gobernador de Buenos Aires, Manuel Dorrego, los negocios de guerra y las relaciones exteriores. Esta medida era urgente porque las provincias argentinas se encontraban en guerra con el imperio del Brasil desde 1825. Aunque el gobierno de Buenos Aires había ya representado a las demás provincias frente al exterior, ésta era la primera vez que esa función surgía como producto de pactos entre estados que se consideraban completamente soberanos. ${ }^{13}$ Juan Manuel de Rosas conservó esa delegación mientras gobernó la provincia de Buenos Aires. A lo largo de su mandato fue ampliando las atribuciones del encargado de Relaciones Exteriores, al punto de avanzar de hecho sobre atributos de la soberanía que las provincias no habían delegado originalmente en esa magistratura.

En materia eclesiástica al menos, ese avance no fue producto de una mera imposición a los gobiernos provinciales. En varias ocasiones los mismos gobernadores recurrieron al encargado para que resolviera conflictos que ellos no podían solucionar en razón de lo limitado de sus jurisdicciones. Aunque los conflictos más arduos se desencadenaron en la región cuyana, los obispados de Córdoba y de Salta también vivieron litigios que buscaron su resolución en el despacho del gobernador porteño.$^{14}$ Frente a la frecuencia de los reclamos, Rosas buscó formalizar ese papel arbitral mediante un procedimiento que, según manifestaba, pondría fin a estas reyertas. En febrero de 1837 emitió, como gobernador de la provincia de Buenos Aires, un decreto en el que se otorgaba a sí mismo, en tanto encargado de las Relaciones Exteriores, la exclusiva potestad de conceder el pase o exequatur necesario para que rigiera en el territorio cualquier «Bula, Breve, ò Rescripto Pontificio». Sin la venia del encargado ninguna persona civil o eclesiástica de la provincia podría reconocer cualquier «nombramiento, creacion, ereccion ò institucion, que se haya hecho, o que se pretenda hacer en esta Provincia, o en cualquiera parte del territorio de la República...», «mediata o inmediatamente [por] Su Santidad, el Romano Pontífice, o [...] la Curia Romana, o [...] algun otro cuerpo o persona que se crea autorizada por Su Santidad». El vigor del decreto era retroactivo a todas las disposiciones romanas que hubieran ingresado a la provincia des-

13 Las alternativas del manejo de las relaciones exteriores han sido acabadamente estudiadas por Tau Anzoátegui, 1996.

14 Bruno, 1966-1976. 
de el 25 de mayo de 1810. Quedaban exceptuadas aquellas disposiciones papales que se refirieran al ámbito de la conciencia o penitencial. ${ }^{15}$

Aunque esta norma sólo podía tener vigencia provincial, las alusiones en los considerandos del decreto a las discordias y divisiones entre «algunos pueblos de la República», a los «intereses generales de la Nacion» y a los deberes de «todos los Gobiernos de la Confederación», sugieren que el Restaurador tomó la medida en vistas a asegurar su acatamiento en las demás provincias. Para conseguir este objetivo envió el decreto a todos los gobernadores, acompañado por una circular donde expresaba su deseo de que cada gobierno emitiera una disposición similar a la que se había dado la provincia de Buenos Aires. ${ }^{16}$ De esa manera, todos los gobernadores prohibirían la aceptación de las disposiciones papales sin el exequatur previo del encargado de Relaciones Exteriores. Si cada provincia emitía una ley idéntica, la norma provincial se hacía, de hecho, supra provincial sin lesionar las formas de la Confederación. ${ }^{17} \mathrm{El}$ prurito federal del gobernador de Buenos Aires parece no haber sido necesario para sus colegas. No sólo prestaron obediencia a esa disposición, sino que consideraron suficiente para otorgarle vigor el hecho de dar publicidad en sus provincias al contenido del decreto. ${ }^{18}$

Según lo manifestó en la circular que acabamos de citar, Rosas emitió el decreto con el propósito de acabar con el «...desorden e informalidad con que se marcha pidiendo Obispos a Roma, y prestando obediencia y cumplimiento a las Bulas, Breves y Rescriptos Pontificios sin el pase o exequatur de la autoridad encargada de las Relaciones Exteriores...». ${ }^{19}$ A renglón seguido, el restaurador pasó revista a los conflictos que había provocado esa desorganización en todas las diócesis y advirtió que el papa «...al ver el desorden como nos conducimos no querrá jamás entrar en ningún arreglo ni Concordato general con respecto a los negocios con nuestra

15 Registro Oficial de la Provincia de Buenos Aires (ROPBA), año 1837, 125, 128.

16 Archivo General de la Nación, Buenos Aires (AGN), X-25-3-6, notas remitidas por Juan Manuel de Rosas a los gobernadores de La Rioja, San Juan, Salta, San Luis y Jujuy, todas fechadas en Buenos Aires, el 28 de febrero de 1837. Su contenido es casi idéntico y coincide con las publicadas por Sierra, 1969, 634.

17 Para una interpretación diferente del alcance del decreto, ver Ayrolo, 2007, 88-92.

18 De la efectividad del decreto en la Confederación da cuenta Bruno 1966-1976. Sobre la entrada en vigencia del decreto en San Juan luego de su publicación el 5 de abril, ver la nota de Manuel Eufrasio de Quiroga Sarmiento al encargado pontificio de negocios en Río de Janeiro Domenico Fabbrini, Buenos Aires, 17 de diciembre de 1837, ASV, Arch. Nunz. Brazile, 268, 34-35.

19 Rosas a Ibarra, Buenos Aires, 28 de febrero de 1837, en Sierra, 1969, 634. 
Iglesia...» ${ }^{20}$ Si no se daba término a esas prácticas, advertía, «...nos vamos a ver envueltos en un caos de que no podremos salir eternamente». ${ }^{21} \mathrm{La}$ existencia de una única autoridad que regulara la comunicación entre la Santa Sede y las provincias confederadas frustraría, además, los intentos de oportunistas «que como ratones de caza andan alrededor de las Oficinas», en las provincias rioplatenses y en Roma, vendiendo sus servicios a los pretendientes a la mitra, aprovechando la desorganización de las comunicaciones con la Santa Sede para hacer decir al papa «lo que ni habrá imaginado decir y hablando de asuntos que no tendrá la menor noticia, o que si la tiene, será por las mentiras y narraciones falsas que le habrán hecho». ${ }^{22} \mathrm{El}$ encargado de Relaciones Exteriores debía disciplinar a las provincias y ser el único interlocutor del sumo pontífice para brindarle una orientación confiable en las medidas a tomar respecto de las diócesis argentinas.

El decreto de 1837 es importante porque plantó las bases legales para alcanzar esos objetivos y lo hizo de una manera novedosa: en primer lugar, instauró una autoridad civil supraprovincial para el gobierno de las iglesias rioplatenses, respetando formalmente la organización confederal; en segundo lugar, lo hizo defendiendo la potestad del papa para gobernar todas las iglesias del orbe católico. Cuando el gobernador de Santiago del Estero, Felipe Ibarra, manifestó su satisfacción frente al decreto celebrando lo que el santiagueño creía una medida destinada a frenar los avances de la autoridad romana sobre los derechos de la soberanía nacional en materia eclesiástica, Rosas respondió rechazando de plano todas las afirmaciones regalistas del gobernador santiagueño. ${ }^{23} \mathrm{La}$ extensísima carta que dirigió a Ibarra vuelve a achacar a los gobernadores la responsabilidad del

20 Idem.

21 Idem. Los conflictos habían surgido en casi todas las diócesis de la Confederación. La creación primero del vicariato y luego de la diócesis de Cuyo no sólo había provocado la reacción de Mendoza y San Luis, sino que antes había ocasionado la resistencia y protestas de las autoridades civiles y eclesiásticas cordobesas, que perdían con esta medida una parte importante del territorio de su diócesis. En ese mismo obispado de Córdoba, el nombramiento papal de un vicario apostólico para gobernarlo en 1830 ocasionó las resistencias del clero local y del gobernador (que no lo había propuesto). En Salta, el nombramiento en 1835 de un vicario apostólico proveniente de la provincia de Tucumán, que pertenecía al obispado pero que no alojaba a su sede, provocó las resistencias del gobierno salteño, donde residían las autoridades de la diócesis. Bruno, 1966-1976, IX.

22 Sierra, 1969, 634.

23 El gobernador de Santiago del Estero denunciaba la excesiva injerencia de la Santa Sede y, particularmente, del nuncio de Brasil («un encapotado que está en el Janeyro») en la diócesis salteña. AGN, X-25-3-6, doc. 257, Ibarra a Rosas, Santiago del Estero, 6 de abril de 1837. Véase también Felipe Ibarra a José Agustín Molina, Santiago del Estero, 23 de noviembre de 1836, AGN, X-25-3-6, doc. 646 (contiene error de datación: se consigna 1837, la fecha correcta es 1836). 
caos eclesiástico: «Los males que ha empezado a sentir nuestra Iglesia desde que nos hemos puesto en comunicación con la Silla Apostólica, no han procedido de la Curia Romana [...] sino del desgreño con que se han manejado entre nosotros los asuntos eclesiásticos, tirando cada Gobierno Provincial por su lado...». ${ }^{24}$ En esta respuesta, Rosas lamentaba que Ibarra se hubiera dejado seducir por «ciertos fariseos» que no son más, advertía, que lobos en piel de cordero que se esforzaban en difamar al pontífice con la excusa de la defensa del Estado. ${ }^{25}$ Y tras la reconvención vino la lección: era erróneo considerar el patronato como una prerrogativa de todo poder soberano. Aunque fuera cierto que los poderes temporales tenían la obligación de proteger y fomentar la religión del estado, y que los cargos eclesiásticos debían ser desempeñados por personas que inspiraran la confianza del gobierno, ello no otorgaba a la autoridad civil el derecho de nombrar a las personas que ocuparían las dignidades eclesiásticas. Tal privilegio sólo podía ser concedido por el pontífice. El patronato que detentaban los reyes españoles había sido otorgado por el papa, y los gobiernos independientes de América debían procurarse una concesión similar para ejercer ese derecho. ${ }^{26}$

Estas reflexiones de Rosas son muy importantes, primero, porque marcan un cambio en las bases doctrinales que habían defendido los gobiernos de Buenos Aires hasta ese momento, de fuerte raigambre galicana. En segundo lugar, porque esta postura intransigente enmarcó ideológicamente el decreto de 1837, que es considerado por la bibliografía de corte más tradicional como uno de los hitos del regalismo rosista. ${ }^{27}$ ¿Cómo explicar esta contradicción? La clave está en que el decreto de 1837 no otorgaba al encargado de Relaciones Exteriores el patronato, que había sido la principal figura del corpus regalista. ${ }^{28}$ De hecho, no se menciona el patro-

24 AGN, X-25-3-6, 438, Rosas a Ibarra, Buenos Aires, 31 de mayo de 1837, publicada en Sierra, 1969, 635-642.

25 Idem.

26 Idem. Esta posición había sido sostenida a comienzos de la década de 1830 por el primo y consejero de Rosas, Tomás Manuel de Anchorena. Ver Agrelo, 1886, 368-411.

27 Llamo «discurso intransigente» a aquel que rechaza la intervención del poder civil en el gobierno eclesiástico y sostiene que la autoridad del papa sobre la iglesia católica no es sólo moral y espiritual, sino también jurisdiccional (Di Stefano, 2004, 167-177). Utilizo el término «regalista» para denominar a las posturas que reivindicaban las regalías que había gozado la corona española sobre sus iglesias en América, sin otorgarle la carga peyorativa que adoptó al ser utilizado por quienes denunciaron en estas atribuciones un avance indebido del poder temporal sobre el espiritual.

28 La idea errónea de que el decreto de 1837 erigió formalmente a Rosas en patrono nacional está muy extendida. Tau Anzoátegui (1996, 93-102) ofrece una interpretación más sensible a los límites del decreto. 
nato en el texto del decreto. Ello le permitió a Rosas erigirse en defensor de los derechos papales frente a la tradición galicana de los gobiernos rioplatenses. ${ }^{29}$

Así y todo, las interpretaciones que adjudican a Rosas una política tan o más regalista que la de los gobiernos previos no son del todo infundadas. Este gobernante no dejó de utilizar los muchos instrumentos que la tradición jurídica hispana le daba para gobernar las iglesias argentinas y que sus antecesores - a quienes criticaba con acrimonia- habían usado también. ¿Por qué buscaba Rosas romper discursivamente con la tradición galicana si seguía utilizando algunas de sus principales herramientas para conservar el control sobre las estructuras eclesiásticas? Existen varias respuestas. En primer lugar, la adopción de criterios eclesiológicos opuestos a los que habían sostenido los gobiernos de Buenos Aires desde el año 1820 era parte de la política semántica rosista de asignar atributos a unitarios y federales siguiendo la lógica del antagonismo inconciliable. ${ }^{30}$ En ese sentido, Rosas procuró convertir en rasgos esenciales de los unitarios aquellas características que les habían granjeado la antipatía general ${ }^{31} \mathrm{El}$ efecto se complementaba asignando a su gobierno federal los atributos opuestos: si los unitarios eran impíos por haber implementado políticas regalistas, el federalismo rosista sería devoto protestando adhesión a la autoridad pontificia. ${ }^{32}$ En segundo término, dentro de la provincia de Buenos Aires, Rosas había ejercido el control de la estructura diocesana apoyando al sector del clero menos afecto a la tradición regalista y reforzando la figura de Mariano Medrano - veterano defensor de la autoridad papal frente a las reformas galicanas de los años 1820s- en sus potestades de obispo nombrado por la Santa Sede, para debilitar al Senado del clero (nombre que recibía el cabildo eclesiástico en Buenos Aires) que no le era afecto. ${ }^{33}$ En tercer lugar, la concentración de la autoridad eclesiástica en el sumo pontífice le facilitaba también el control sobre las demás diócesis argentinas, en la medida en que Rosas monopolizaba la comunicación entre esas iglesias

29 Di Stefano, 2006.

30 Salvatore, 1998; Myers, 1995.

31 Sobre la política religiosa del grupo rivadaviano, luego devenido en unitario, puede consultarse Di Stefano, 2008 y, en discusión con este artículo, Barral, 2009.

32 La demonización de los unitarios estaba a cargo en gran parte del clero de la provincia de Buenos Aires, Barral, 2008.

33 Di Stefano, 2004. El mismo autor destaca las contradicciones irresolubles que pronto se plantearon entre el discurso intransigente de Rosas y la concepción galicana con que gobernaba la iglesia porteña. Di Stefano, 2006. Acerca de la creciente presión rosista sobre el clero de su provincia: Barral, 2008. 
y el papa sin amenazar formalmente las prerrogativas eclesiásticas que reclamaban los gobiernos provinciales. Téngase en cuenta que, aunque el encargado de Relaciones Exteriores se pronunció en contra del ejercicio del patronato como prerrogativa del poder soberano, su decreto no avanzó sobre los derechos patronales que reivindicaban las provincias en tanto soberanas.

En síntesis, al no hacer mención al patronato, Rosas podía justificar sus atribuciones en materia eclesiástica y erigirse al mismo tiempo en defensor de los principales derechos que reivindicaba la Santa Sede sobre las iglesias del mundo católico. ${ }^{34}$ También se resguardaba de la acusación de violar las prerrogativas que la organización confederal reservaba a las provincias. Pero, aunque no pudiera hacerlo explícito, esta disposición le otorgaba una especie de patronato nacional de hecho, al menos en el nombramiento de obispos, porque sin el consentimiento del encargado de Relaciones Exteriores las bulas de institución episcopal que enviaba el papa desde Roma no tendrían validez. De allí que cualquier candidato a la mitra debía contar con la aprobación de Rosas para ser instituido.

\section{El Encargado de Relaciones Exteriores como árbitro de las disputas interprovinciales}

Las medidas que adoptó Rosas habilitado por este decreto tuvieron impacto en el corto, pero también en el mediano y largo plazos. En lo inmediato, tomó decisiones orientadas a solucionar los problemas jurisdiccionales que se sucedían desde los años 1820s y, al hacerlo, avanzó sobre las atribuciones de los gobiernos provinciales en materia eclesiástica. En el más largo plazo, esas disposiciones dictadas por la coyuntura sentaron un precedente y delinearon un marco institucional y normativo para el gobierno de las Iglesias en la Confederación. Se analizarán en orden estos dos aspectos.

En primer lugar, Rosas se propuso solucionar el conflicto que se había desencadenado en la diócesis de Cuyo. Este obispado, creado a comienzos de la década de 1830, abarcaba las provincias de San Luis, Mendoza y San Juan, pero en los trámites de su erección frente a la Santa Sede sólo

34 No de todos los derechos que reivindicaba el papa, porque el pase o exequatur en manos de los poderes civiles no era reconocido en Roma como un atributo legítimo de la autoridad temporal. 
habían participado las autoridades sanjuaninas, sin intervención de los demás gobiernos involucrados. Ello ocasionó el descontento de estas autoridades, particularmente del gobierno mendocino, que tenía desde antiguo el deseo de ver instalada en su capital la sede episcopal. ${ }^{35}$ Era porque el gobierno que alojara a las autoridades diocesanas podría condicionarlas mediante el ejercicio del patronato y así extender en materia eclesiástica su poder jurisdiccional más allá de las fronteras de la provincia, hasta donde alcanzara el territorio del obispado. Consciente de ello, Rosas buscó poner coto a las pretensiones sanjuaninas. Lo hizo apoyado en el respeto a las autonomías provinciales: en uso de las facultades que le daba el decreto de 1837, otorgó el pase a las bulas de creación del obispado de Cuyo pero sólo para San Juan, dejando en libertad a las provincias de Mendoza y San Luis para mantenerse dentro de la diócesis de Córdoba - jurisdicción eclesiástica a la que pertenecían antes de crearse el obispado de Cuyo- o aceptar su inclusión en la cuyana. ${ }^{36}$

De todas maneras, las pretensiones autonómicas de las provincias en materia eclesiástica encontraban su límite en la debilidad de las mismas provincias antes que en la fortaleza de poderes externos. Las estructuras fiscales e institucionales de la mayoría de ellas sustentaban a duras penas una escuálida red parroquial, aunque las necesidades políticas de sus autoridades las impulsaran constantemente a solicitar el obispado propio. ${ }^{37}$ Aquí entró a tallar la segunda función del encargado de Relaciones Exteriores: no sólo dirimía conflictos interprovinciales, sino que podía evitar modificaciones jurisdiccionales inviables en las iglesias argentinas. Es posible graficar esta función con un ejemplo elocuente.

Si había una provincia incapaz de sustentar una diócesis, ésa era la de San Luis. Consciente de ello, su gobernador se propuso, al menos, conseguir de Roma el nombramiento de un obispo auxiliar sin separarse de la diócesis cuyense. Con ese propósito se dirigió en 1835 directamente a la Santa Sede, sin consultar ni dar aviso al encargado de Relaciones

35 Ver Juan Manuel de Rosas al gobernador de San Luis, 31 de enero de 1837, en Verdaguer, 1932, II, 213-215. Véase también, vista del fiscal de San Luis sobre este conflicto y respuesta del gobernador de la misma provincia al obispo J. M. E. Quiroga Sarmiento, ambos documentos sin fechar y sin foliar, en AGN, X-25-3-6. La respuesta al gobernador de Mendoza, Pedro Molina, fechada el 20 de diciembre de 1836, está reseñada en Bruno, 1966-1976, IX, 424-425.

36 Decreto del encargado de Relaciones Exteriores, Buenos Aires 18 de octubre de 1839, Registro Oficial de la República Argentina (RORA), Buenos Aires, 1880, II, 404-405.

37 La pobreza de las iglesias provinciales está muy documentada. Para no multiplicar las citas, remito a Auza, 1981. 
Exteriores..$^{38}$ No tenía en ese momento la obligación de hacerlo, puesto que todavía no existía el decreto de febrero de 1837. Sin embargo, el trámite se retrasó, y el gobernador de San Luis no recibió las bulas de institución de su candidato, José Hilarión Etura, hasta mayo de 1840. Inmediatamente las remitió a Buenos Aires solicitando el pase pero, con el argumento de que el trámite había sido iniciado sin intervención del encargado de las Relaciones Exteriores, Rosas negó el exequatur a las bulas. ${ }^{39}$ Al mismo tiempo, el obispo auxiliar de Buenos Aires remitía un informe a Roma considerando inoportuno el nombramiento de un obispo en una jurisdicción tan pobre como la de San Luis, que a duras penas podía mantener económicamente su ínfima iglesia. ${ }^{40}$ Ese no era el único inconveniente; algunos años después, el obispo cuyano descubrió en su visita que el frustrado mitrado no sólo administraba pésimamente su curato, sino que su comportamiento personal estaba muy lejos de honrar el orden sacerdotal. ${ }^{41}$ En este episodio Rosas demostró que su intervención en el gobierno eclesiástico moderaba los efectos perniciosos de aquel «...desorden e informalidad con que se marcha pidiendo Obispos a Roma...». La negativa a dar el pase a las bulas de Etura corrigió el error papal de haber nombrado a una persona evidentemente no apta para la dignidad episcopal en una región que no podía sustentar sus costos.

Que para Roma el regalismo rosista representaba el mal menor, e incluso necesario, lo prueban los mismos documentos pontificios. Cuando Giovanni Mastai Ferretti fue elegido papa en junio de 1846 con el nombre de Pío IX, el gobernador de Mendoza, Pedro Pascual Segura — que lo había conocido personalmente cuando visitó la ciudad de Mendoza como secre-

38 Véase Bruno, 1966-1976, X, 107.

39 Ibidem, 107-114.

40 Ibidem, 110. En agosto de 1840, Escalada compartió su preocupación con su amigo Fabbrini. Le recordó las paupérrimas condiciones de la provincia de San Luis, cuyo pueblo «apenas puede llamarse aldea» (66v.). Le advirtió que sólo había un cura (el que fue nombrado obispo), que con serias dificultades estaba desde hacía unos años construyendo un templo, y un miserable convento dominico con uno o dos frailes. El nuevo obispo estaría entonces sin clero, sin rentas y sin ministros que pudieran servirlo. (Escalada a Fabbrini, Buenos Aires, 24 de agosto de 1840, ASV, Arch. Nunz. Brasile, 264, 66-67). También el clérigo mendocino José Antonio Sosa se mostraba alarmado por la decisión de la santa sede. Consideraba insólita la institución de un obispo para San Luis, cuando no había allí ni curas. Con suspicacia comentaba a su amigo Castro Barros que «esto mas parece merienda de negros, q. prohibiciones Pontificias»; era evidente, afirmaba Sosa, que habían engañado al sumo pontífice. Sosa a Castro, Mendoza, 1 de diciembre de 1837, ASV, Arch. Nunz. Brasile, 272, 94-97.

41 Véanse los autos de la visita episcopal fechados en San Luis el 16 de octubre de 1843, en Verdaguer, 1932, II, 268-271. Allí el obispo comprobó que Etura no llevaba al día los libros parroquiales, vivía amancebado y pesaban sobre él varias acusaciones de solicitación. 
tario de la misión Muzi- se decidió a escribirle solicitándole el nombramiento de un prelado para su provincia. La petición preveía dos instancias: en primer lugar, el nombramiento de un obispo auxiliar en Mendoza, y en un segundo momento, la creación de una diócesis independiente del de San Juan. ${ }^{42} \mathrm{Al}$ igual que había ocurrido con San Luis, la decisión de elevar una nota oficial al sumo pontífice sin el visado previo del encargado de Relaciones Exteriores fue considerada por Rosas un acto frontal de desconocimiento de su magistratura. Para evitar que esta situación se repitiera, el gobernante remitió una nota a Roma informando que la legislación existente en la Confederación sólo consideraba válida la correspondencia enviada a la curia pontificia por intermedio del encargado de Relaciones Exteriores. No omitió informar también que toda disposición papal debía contar con el pase o exequatur de esa misma autoridad para regir en la Confederación. ${ }^{43}$

Las pretensiones del gobernante no podían sino incomodar a la curia romana. La Sagrada Congregación de Asuntos Eclesiásticos Extraordinarios trató conjuntamente la solicitud del gobernador mendocino y la nota enviada por Rosas en mayo de 1848. Para ese entonces, el gobernador Segura había renunciado a su cargo, presionado por facciones opositoras dentro de la provincia apoyadas por Rosas, que ya no confiaba en él. ${ }^{44}$ Las conclusiones a las que llegaron los miembros de la Congregación son sumamente sugestivas. Citamos por ello en extenso las actas de esa reunión:

Después de esta breve exposición, sin dificultad se advierte que el proyecto del gobernador de Mendoza es plausible; pero ¿cómo llevarlo a la práctica habiéndose este dimitido y desdeñando el señor Rosas su cumplimiento?

Más ayuda, por lo mismo, que la Santa Sede entable relaciones con este último, conociendo los principios que lo animan. Pero de elegir esta solución, ¿se podrán pasar por alto los dos citados decretos que el señor Presidente [refiriéndose a Rosas] ha tenido la osadía de trasmitir al supremo Jerarca; decretos gravemente lesivos de su autoridad apostólica?

Como puede apreciarse, los gobiernos provinciales ya no eran considerados interlocutores confiables por la Santa Sede. Las medidas que suge-

42 J. J. Segura a Pio IX, en Bruno, 1966-1976, X, 94 y 95 (extractada y resumida).

43 Rosas a Pío IX, Buenos Aires, 18 de abril de 1847, en Ibidem, 96. En ASV Arch. Nunz. Brasile, 279, 14-17v. se amplían los argumentos en una nota que debía llegar al nuncio en Río; Felipe Arana al ministro plenipotenciario de la Conf. Argentina cerca del Gob. de S. M. el emperador del Brasil, Buenos Aires, 5 de octubre de 1847.

44 Bransboin, 2007; Castro, 1979. 
rían a Roma corrían el riesgo de ser incumplidas o inadecuadas a causa de la facilidad con que esos gobiernos eran desplazados del poder. Rosas, en cambio, había demostrado ya sobrada capacidad para conservar el gobierno de su provincia e imponerse a las otras. Por otro lado, el consentimiento de Rosas era indispensable para la actuación del obispo Escalada, pieza clave de la red de sacerdotes confiables que la Santa Sede proyectaba en el sur de América.

Con el correr de los años, esta circunstancial coincidencia entre el encargado de Relaciones Exteriores y el sumo pontífice se fue disolviendo a medida que cada una de las partes se consideraba con la fortaleza suficiente para prescindir de la otra. De hecho, no se vuelve a encontrar durante la década de 1840 una defensa tan argumentada y decidida de la autoridad papal en los documentos oficiales del encargado de las Relaciones Exteriores. En su lugar, fue cobrando mucha mayor entidad el concepto de patronato nacional.

El cambio obedece en parte a la modificación de las circunstancias que habían favorecido el discurso intransigente en Rosas. La actividad de los opositores en los países limítrofes le ofreció la oportunidad de redefinir los rasgos negativos que adjudicaba a los unitarios, acusándolos ahora de conspiradores contra la independencia de la nación. La imputación de impíos seguía operando, pero su efectividad podía flaquear en la medida en que los sucesos que le servían de referente se perdían en el pasado. La autoridad de Medrano, por su parte, se debilitaba aceleradamente en la diócesis, al tiempo que se fortalecía la figura de su obispo auxiliar, Mariano Escalada, tanto menos dispuesto a complacer los deseos del gobernador cuanto más propenso se demostraba a implementar la política romana de centralización del gobierno de la iglesia católica. ${ }^{45}$

\section{Institucionalización de la autoridad nacional}

A estos factores se suma la gradual consolidación de la autoridad rosista en el resto de las provincias de la Confederación. ${ }^{46}$ En el plano ecle-

45 Luego de haber habilitado el ingreso de la Compañía de Jesús entre 1835 y 1837, Rosas resolvió expulsar a los jesuitas en 1843. Ello provocó la definitiva ruptura con Escalada, con quien las relaciones se venían enfriando aceleradamente. Sobre la labor de los jesuitas en la provincia de Buenos Aires, puede consultarse Di Stefano y Barral, 2008, para ampliar sobre las oscilaciones de la política rosista en Buenos Aires, Di Stefano, 2006.

46 Halperín Donghi, 1972, 338-379; Salvatore, 1998; Ternavasio, 2009. 
siástico, esa autoridad se cristalizó en una serie de normas y procedimientos de gobierno que, a fuerza de repetirse, adquirieron cierto grado de institucionalización a escala supraprovincial. Uno de los procedimientos donde se advierte esta tendencia es el juramento que se exigía a los obispos nombrados por Roma para conceder el pase a sus bulas. En él se comprometía el futuro mitrado a sostener y defender la libertad y la independencia de la República bajo el régimen federal, prestar obediencia y sumisión a las leyes y respetar los derechos consiguientes a la soberanía, no mantener comunicación con proyectos que amenazaran la seguridad de la república, instar a la población al uso de la divisa punzó, no aceptar distinción ni dignidad alguna sin permiso previo del «Gobierno General de la República, o del que haga sus veces en toda ella», no dar cumplimiento a ninguna disposición pontificia sin el previo consentimiento del encargado de Relaciones Exteriores, no recurrir ni permitir que otra persona de su diócesis recurriese a Roma sin previo permiso del encargado. ${ }^{47}$ En resumen, a falta de un marco legal que estableciera claramente las obligaciones de las máximas autoridades eclesiásticas frente a lo que con creciente frecuencia se llamaba autoridad nacional, el juramento suplía la norma al obligar con similar fuerza. Si ese juramento se repetía en los mismos términos para cada nuevo obispo, todos ellos estarían atados a idénticas obligaciones, y así el gobierno gozaría de prerrogativas homogéneas sobre los obispos de las diócesis argentinas.

De esta manera, el decreto de 1837 funcionó como plataforma para esbozar, a partir de las condiciones que Rosas imponía para otorgar el pase, una suerte de marco normativo nacional sin necesidad de una legislatura. Cuando las leyes no existían, suplió al poder legislativo emitiendo decretos o estableciendo normas paralegales, como ocurrió con el juramento. ${ }^{48}$ En otras ocasiones, hizo las veces de ejecutivo nacional exigiendo el cumplimiento de una norma sancionada por una legislatura nacional ya extinta. Asumiendo este rol, Rosas retrasó el pase a las bulas de erección del obispado de Cuyo porque, entre otras cosas, el acuerdo que habían firmado el gobernador de San Juan con el obispo fray Justo Santa María de Oro para apurar la creación de la diócesis declaraba exclusiva en esa provincia a la 404-405.

47 Decreto de Juan Manuel de Rosas, Buenos Aires, 18 de octubre de 1839, RORA, II,

48 Utilizo la expresión «paralegal» con vistas a encontrar un término que se adecue mejor a la función que cumplió el juramento. 
religión católica, y tal cláusula atentaba contra la tolerancia religiosa sancionada por el Congreso Nacional Constituyente en $1825 .{ }^{49}$

Hacia fines de la década de 1840, la concentración de facultades de gobierno eclesiástico en la autoridad nacional avanzó sustancialmente. En junio de 1849, a instancias de un conflicto desatado en la diócesis de Cuyo en torno a la validez de un conjunto de secularizaciones efectuadas por Muzi en los años 1820s., Rosas emitió un decreto que complementaba al de 1837 incluyendo a los rescriptos de secularización en el conjunto de disposiciones pontificias que debían contar con el pase regio del encargado de Relaciones Exteriores. ${ }^{50}$ Aunque esta medida fue evaluada por la historiografía que ha tratado el tema como un claro avance sobre prerrogativas papales, en realidad no significaba un despojo de facultades que la Santa Sede hubiera ejercido previamente, ${ }^{51}$ pues desde la llegada de la iglesia católica a América, este tipo de trámite estaba fiscalizado por los poderes civiles. Incluso los tímidos gobiernos provinciales habían impuesto el pase a los rescriptos de secularización en la década de $1820 .^{52}$

Es en este punto donde la ampliación de las atribuciones que sancionó el nuevo decreto constituyó un cambio sustancial. Ya no se trataba, como había ocurrido en 1837, de asumir el lugar arbitral que ningún gobierno provincial podía ocupar. El hecho de que los rescriptos fueran emitidos por autoridades externas al territorio sirvió de excusa para controlar aspectos de gobierno que poco que ver tenían con las relaciones exteriores. El decreto de 1849 dejó en manos de la autoridad supraprovincial la

49 AGN X-17-2-1, Rosas a Nazario Benavídez, Buenos Aires, 15 de mayo de 1839; sobre la tolerancia: Calvo, 2004 y Di Stefano, 2008. A pesar de esta pretensión de nacionalizar la tolerancia de cultos, las constituciones provinciales siguieron excluyendo en muchos casos la posibilidad de celebrar cultos diferentes al católico en sus territorios (agradezco a uno de los evaluadores de este artículo esta observación).

50 Los rescriptos de secularización eran la autorización que extendía el papa —o autoridades delegadas - a los religiosos que querían abandonar su orden para sumarse al clero secular. El decreto de 1849 estuvo precedido por sendos dictámenes del fiscal, del asesor de gobierno y de la curia de Buenos Aires. Ver Eduardo Lahitte, «Dictámen del Fiscal del Estado del Gobierno de Buenos Aires, sobre la cuestión suscitada en la Provincia de San Juan con motivo de algunos breves de secularizacion», Buenos Aires, 26 de enero de 1848, y Baldomero García «Dictamen del Asesor General del Gobierno de Buenos Aires», Buenos Aires, 19 de septiembre de 1848, RORA, II, 452-465.

51 Las visiones clásicas en Legón, 1920; Zuretti, 1972 y Bruno, 1966-1976, entre otros.

52 Martínez Paz, 1938. En Córdoba, Rosas no esperó hasta 1849 para experimentar este avance de atribuciones sobre el gobierno provincial: sobre la base del decreto de 1837, otorgó en 1844 el pase para exclaustrar a Sor María de Jesús ó Faustina de San Juan Bautista del convento de las monjas catalinas. Esta medida fue utilizada como antecedente para el decreto de 1849. Ver en AGN X-5-8-4, nota del obispo de San Juan a Felipe Arana, San Juan, 26 de septiembre de 1845 y el visto bueno del ministro, Buenos Aires, 7 de diciembre de 1845. 
política de secularizaciones que las provincias habían manejado desde 1820. El traslado de sacerdotes del clero regular al secular permitía a las autoridades civiles y eclesiásticas de las provincias proveer de pastores a su despoblada estructura parroquial. Se trataba, por lo tanto, de un punto muy sensible de la política interna provincial, que ahora quedaba en manos de Rosas. Las repetidas menciones a un «Gobierno Nacional» o «encargado de la Direccion suprema de los asuntos nacionales de la Confederacion Argentina» reflejaron ese viraje de la magistratura de Rosas, que ya no restringía sus atribuciones al manejo de las relaciones exteriores, sino que avanzaba sobre facultades de los gobiernos provinciales, convertidas ahora en «asuntos nacionales».

Los argumentos con que se justificó este decreto reforzaron todavía más la tendencia a construir la figura del patrono nacional, y a imponer un cuerpo normativo supraprovincial para constreñir el margen de acción de los gobiernos provinciales. El fiscal de la provincia de Buenos Aires, Eduardo Lahitte, en el dictamen que sirvió de plataforma legal al decreto, asignó abiertamente facultades patronales a la magistratura confederal:

Aunque el ejercicio del patronato nacional reside en el Exmo. Gobierno Encargado de las Relaciones Exteriores, en todo lo que está ligado con dichas Relaciones, los Exmos. Gobiernos de las Provincias retienen y ejercitan, en sus respectivos territorios, el mismo patronato, fuera de los casos exceptuados que acaban de notarse, es decir, de aquellos que afectan las Relaciones Exteriores del Estado. ${ }^{53}$

Detrás de este reconocimiento a la autoridad provincial se escondía una nueva distribución de las facultades patronales que no se había planteado de manera explícita en 1837. Rosas, no sólo era encargado de Relaciones Exteriores, sino que también estaba investido con las facultades del patrono nacional. Baldomero García, asesor del gobierno de Buenos Aires, fue más categórico a la hora de fortalecer la autoridad nacional:

Todas las bulas, breves y rescriptos pontificios, todas absolutamente las letras emanadas, mediata ó inmediatamente, de su Santidad el Soberano Pontifice, necesitan el pase ó exequatur de V. E., a quien está encargado, por sancion expresa de las Provincias todas de la Confederacion Argentina, de conformidad al pacto constitucional, el Gobierno Supremo de la Nacion en varios ramos, entre ellos el de Relaciones Exteriores. ${ }^{54}$

53 Lahitte, «Dictamen del Fiscal...», 135, 26 de enero de 1848, ROPBA, año 1848, 127-146.

54 Dictamen del Asesor General del Gobierno de Buenos Aires, Baldomero García, fechado el 19 de septiembre de 1848, 148, ROPBA, 1848, 147-182. 
Las afirmaciones de García van mucho más lejos que las de Lahitte. La utilización del término «pacto constitucional» y la idea de que el gobierno supremo de la Nación incluía no sólo el manejo diplomático sino otros varios ramos, funcionaron como performativo, porque no existía en realidad un pacto que hubiese constituido un gobierno nacional con atribuciones que excedieran a las diplomáticas.

En parte esta operación era posible porque el «lenguaje nacional» contaba ya con cierta tradición en el discurso político argentino. La utilización de términos que remitían a una identidad o comunidad política nacional se había hecho frecuente a comienzos de la década de 1830, en el momento de la firma del Pacto Federal suscripto por las provincias argentinas para reglar sus relaciones hasta tanto se sancionara una constitución para ese espacio mayor. ${ }^{55}$ Los funcionarios rosistas de fines de los 1830s. y 1840s. no dudaron en retomar ese lenguaje cuando advirtieron que podía brindar legitimidad al orden supraprovincial que estaban construyendo, más aún cuando la paulatina expansión de discursos y sensibilidades románticas en este mismo periodo dotaban al discurso político nacional de un contexto semántico más amplio y complejo. ${ }^{56}$ Sumado a esto, los dictámenes fundamentados del fiscal de la provincia de Buenos Aires y del asesor del gobierno, que en ocasiones se respaldaron en otros de la autoridad eclesiástica de Buenos Aires, fueron un elemento más en ese proceso de institucionalización de la autoridad nacional. Su presencia legitimaba jurídicamente las decisiones del encargado desde el derecho civil y el canónico.

\section{El poder nacional, el papa y las provincias}

Aunque esta combinación sui generis de decretos, dictámenes, procedimientos burocráticos y habilidad política le permitió a Rosas consolidar su autoridad nacional avanzando sobre las autonomías provinciales en

55 Véase Chiaramonte, 1992, 231-246. De este trabajo tomo la expresión «lenguaje nacional».

56 A comienzos de la década de 1830, muchos de los principales dirigentes unitarios y federales invocaban los intereses de la Nación o la República Argentina (refiriéndose ya no a Buenos Aires, sino a todo el territorio de las antes llamadas Provincias Unidas del Río de la Plata) para justificar la necesidad de una constitución nacional. Esa tendencia fue contrarrestada y finalmente derrotada por el federalismo porteño encabezado por Rosas en una coyuntura en la que su poder todavía no estaba consolidado en las demás provincias (Chiaramonte, 1992, 231-246). Sobre la corriente romántica: Chiaramonte, 1992, 247-257; Myers, 1998; Souto y Wasserman, 2008. 
materia eclesiástica, su capacidad de gobernar las iglesias argentinas experimentó ciertas restricciones que tenían origen en la irrenunciable organización confederal sobre la que este gobernante construyó su poder.

Esos límites se sintieron en la provincia de Corrientes, siempre díscola a la influencia rosista. A comienzos de la década de 1840, tras retirar a Rosas el encargo de las relaciones exteriores en 1841, el gobernador Pedro Ferré estableció comunicación con el internuncio en Río de Janeiro, Ambrosio Campodonico, para solicitarle el nombramiento de un vicario apostólico con facultades episcopales destinado a asistir espiritualmente a la feligresía correntina, que hacía años no recibía la visita de su prelado y que pocas perspectivas tenía de revertir la situación, dada la incomunicación con la sede diocesana en Buenos Aires. ${ }^{57}$ El trámite quedó trunco tras la derrota de las fuerzas antirrosistas y la huida de Ferré al Paraguay en diciembre de 1842. Sin embargo, los contactos con Campodonico se reiniciaron a comienzos de 1844, bajo un nuevo gobierno antirrosista encabezado por Joaquín Madariaga. La necesidad de un vicario apostólico era ahora más acuciante porque había muerto el delegado eclesiástico de la provincia, Juan Antonio Acevedo, que poseía facultades delegadas por el obispo de Buenos Aires para gobernar la iglesia correntina, y no quedaban en la provincia autoridades eclesiásticas con más atribuciones que las de los curas párrocos. Este vacío y el enfrentamiento con Rosas crearon la oportunidad, a los ojos de Campodonico, para intervenir directamente en la vida eclesiástica correntina nombrando a un vicario apostólico en la persona de Juan Nepomuceno Goytía. El breve del nombramiento fue expedido en Roma en noviembre de 1845. Así, la Santa Sede nombraba nuevamente un vicario apostólico a petición de un gobierno provincial luego de casi diez años de férreo control rosista en el diálogo con Roma. Pero la experiencia fue muy corta pues una nueva victoria federal forzó al gobierno correntino a volver a la órbita de Buenos Aires. Este viraje en la política interna de la Confederación coincidió con el retiro de Campodonico de la nunciatura en Brasil y el nuevo representante pontificio en América asumió una posición conciliadora con Rosas que, por otra parte, hacia 1847 gobernaba sin oposiciones el territorio argentino. Viendo reducidas nuevamente sus opciones, el gobierno correntino intentó cubrir la falta de autoridad eclesiástica en la provincia solicitando al obispo de Buenos Aires, Medrano, el nombramiento de un delegado eclesiástico.

57 Tonda, 1969. 
Dada la resignada sumisión del prelado a la voluntad del gobernador de Buenos Aires, este recurso era lo mismo que solicitar al mismo Rosas el nombramiento de la máxima autoridad eclesiástica en Corrientes. Desconfiando aún del gobierno de esa provincia, el encargado de las Relaciones Exteriores dilató la provisión de un nuevo delegado eclesiástico. Ante esta demora, el nuevo internuncio en el Janeiro, Caetano Bedini, se decidió a nombrar otro vicario apostólico, ignorando que, pocos meses antes, Medrano había designado finalmente un delegado eclesiástico y, más recientemente aún, Madariaga había sido derrotado de forma definitiva y Corrientes reincorporada sin dobleces a la Confederación. Este nuevo vuelco dejó sin efecto, una vez más, el nombramiento del vicario apostólico y consolidó la potestad de Rosas en materia eclesiástica en todo el territorio.

El incidente con Corrientes prueba que la institucionalización y regularización de los mecanismos del gobierno eclesiástico ensayadas por Rosas estaban limitadas por su misma lógica de construcción de poder. El tenue marco institucional con el que gobernaba más allá de su provincia otorgaba al encargado de Relaciones Exteriores una amplia libertad para premiar fidelidades o castigar disensos. Podía así retardar el nombramiento de un delegado eclesiástico en Corrientes o clausurar la comunicación del nuncio con una provincia en particular. Ese margen de discrecionalidad le aseguraba la obediencia de las autoridades provinciales. Con ese comportamiento había conseguido también que los funcionarios pontificios prefirieran sacrificar la comunicación directa con una provincia (cuya independencia siempre era efímera) para mantenerla con el resto de la Confederación, representada por su encargado de Relaciones Exteriores. Pero todo este mecanismo funcionaba en virtud de un delicado equilibrio entre varios contrapesos: no sólo era posible mientras los distanciamientos de ciertas provincias fueran pasajeros, sino que también requería una relativa buena predisposición del nuncio en Río. Durante la gestión de Campodonico, el carácter intransigente del representante papal en combinación con la escisión correntina, amenazaron con desbaratar el sistema de gobierno eclesiástico que había funcionado en todo el territorio de la Confederación desde fines de 1830. El nombramiento de un nuevo vicario apostólico a pedido de un gobierno provincial parecía retrotraer la situación a la década de 1830 (tan fértil en conflictos), que la imposición del encargado de Relaciones Exteriores había conseguido aplacar. 
Si por un lado la tendencia del gobierno rosista a consolidar un poder central en materia eclesiástica parecía incapaz de superar totalmente los obstáculos que le oponía la tradición autonómica de las provincias argentinas - que el mismo Rosas promovía en beneficio de Buenos Aires-, por el otro comenzó a experimentar hacia fines del periodo una resistencia de nuevo tipo, que anticipaba las dificultades que encontraría todo poder civil para gobernar las iglesias en un contexto de creciente diferenciación de esferas y avance de la autoridad papal en el orbe católico. En 1847 una porción del clero sanjuanino, junto con el obispo Medrano, y, más tímidamente, con el senado del clero porteño, sostuvieron que el trámite de la secularización debía quedar fuera de la jurisdicción temporal y reservado, por lo tanto, a la órbita papal..$^{58}$ Este episodio indica un cambio importante, ya que los sacerdotes, sin distinción de jerarquías ni de diócesis, hablaban en nombre de una Iglesia cuyos intereses estaban representados por el papa. Los argumentos utilizados por el clero eliminaron la distinción entre iglesia local y poder pontificio, tan cara a la tradición galicana. En cambio, tendieron a considerar las pretensiones del poder temporal como amenazas a la libertad eclesiástica.

Al promediar el siglo, la concordia de la década de 1830 entre los defensores de la autoridad papal y Rosas había terminado. En gran parte la ruptura obedeció al vuelco de la política eclesiástica rosista dentro de la provincia de Buenos Aires. ${ }^{59}$ Pero las circunstancias locales estuvieron acompañadas por transformaciones más amplias que afectaron tanto a Roma, como a la autoridad rosista en la Confederación y en el concierto de las demás naciones. La Santa Sede acentuó durante el siglo XIX el proceso de centralización y concentración del poder eclesiástico en todo el mundo católico. El encargado de Relaciones Exteriores, por su parte, gozaba hacia fines de nuestro periodo de una indiscutida primacía política supraprovincial y, tras dos intensos conflictos con Francia y Gran Bretaña de los que había salido airoso, del reconocimiento de las principales potencias atlánticas.

58 AGN X-17-7-7, carta firmada por el provisor de la diócesis cuyana, Vicente Atienzo, el cura rector de la catedral, Miguel Mallea y José María Dávila, en representación de los sacerdotes secularizados por Muzi, al obispo de San Juan, M. E. de Quiroga Sarmiento, San Juan, 4 de marzo de 1847. Ibidem, dictamen del Senado del Clero, fechado en Buenos Aires el 3 de diciembre de 1847, y del obispo Medrano del 6 de diciembre del mismo año.

59 Di Stefano, 2006. 


\section{Conclusión}

El estudio de la política eclesiástica de Rosas permite identificar algunas de las condiciones que favorecieron su gravitación sobre las demás provincias. Se intentó demostrar que en el ejercicio de ese poder cobró forma un entramado de normas y procedimientos que reguló cada vez más el modo en que debían comportarse las autoridades civiles y eclesiásticas argentinas. De esa manera, la magistratura ejercida por Rosas desbordó las funciones de un árbitro entre poderes soberanos autónomos. Primero, porque esos gobiernos provinciales no eran totalmente autónomos ni soberanos en la medida en que fueron incapaces - en su gran mayoría y durante casi todo este periodo- de decidir sobre el nombramiento de los obispos de sus diócesis y, por lo tanto, de ejercer plenamente el patronato, que era una de las atribuciones de la soberanía según los criterios de la época. ${ }^{60}$ Segundo, porque las disposiciones de Rosas no sólo afectaban a estados en disputa, sino que exigían su obediencia a todos los habitantes de la Confederación, formaran parte ellos del conflicto que Rosas debía dirimir o no.

Como se advirtió en la introducción, la existencia de un poder supraprovincial en materia eclesiástica no implica la de un estado nacional y tampoco supone la imposibilidad de las autoridades provinciales de manejar con cierto margen de autonomía sus asuntos eclesiásticos. De hecho, la definición de tal estado no era una preocupación del gobierno rosista pero sí lo fue, tras la caída de Rosas, para quienes se propusieron elaborar y sancionar una constitución nacional. Uno de los grandes desafíos de esta nueva etapa fue otorgar al estado nacional que se estaba constituyendo atributos soberanos que las provincias reivindicaban como propios. Restaría analizar con más detalle en qué medida la experiencia de concentración del poder rosista facilitó la labor de construcción de este estado. En el terreno eclesiástico, la experiencia del periodo de Rosas se extendió con sus grises: no fueron pocas las discusiones donde los antecedentes de esa etapa rosista se utilizaron para avanzar en la construcción del patrono nacional. Tampoco faltaron las resistencias provinciales que contestaron estos inten-

60 Es necesario hacer una aclaración para respetar la complejidad de este periodo: a pesar del consenso que existía sobre el patronato como atributo de la soberanía, el concepto mismo de soberanía estaba en pleno cambio en ese período y era objeto de disputas y nuevas lecturas. A medida que avanzaba el siglo XIX se multiplicaron las voces de quienes sostenían que el patronato no era parte del poder soberano. Un análisis más detallado de estos debates en Martínez, 2010. 
tos reivindicando, también, la tradición confederal que Rosas promovió y que en gran medida hundía sus raíces en las formas coloniales del gobierno civil y eclesiástico. ${ }^{61}$ En uno y otro caso, este enfoque permite hilvanar de manera menos abrupta la historia antes y después de Caseros.

Además, el periplo que recorrió la postura del encargado de Relaciones Exteriores frente a la autoridad pontificia es un indicador de los cambios que se insinuaban durante la primera mitad del siglo XIX en la forma de concebir la relación entre soberanía política e instituciones religiosas. La defensa inicial de Rosas de las prerrogativas papales quitaba al poder soberano la facultad de nombrar al personal eclesiástico de su territorio. Se trata de un paso importante hacia la diferenciación entre instituciones civiles y eclesiásticas que durante la colonia habían estado fuertemente imbricadas. Sin embargo, esa diferenciación fue sostenida mientras sirvió a Rosas para limitar aquellos atributos de la soberanía que los gobiernos provinciales no habían delegado en su persona. Tan pronto como lo creyó conveniente, este gobernante abandonó el respeto por las prerrogativas papales e intentó reconstruir el esquema patronal de la colonia. Pero la situación había cambiado y los argumentos intransigentes ganaban paulatinamente adhesiones dentro del clero local. Frente a estas posturas se hacía cada vez más claro, y no sólo para Rosas, que los poderes políticos surgidos de la crisis colonial deberían reformular su relación con las instituciones religiosas y que el camino no sería apacible.

Recibido el 27 de mayo de 2010 Aceptado el 16 de noviembre de 2011

\section{Bibliografía}

Agrelo, Pedro (ed.): Memorial Ajustado, Buenos Aires, Imprenta, Lit. y Encuad. de La Tribuna Nacional, 1886.

Auza, Néstor: «Los recursos económicos de la iglesia hasta 1853. Antecedentes del presupuesto de culto», Revista Histórica, 8, Buenos Aires, 1981, 3-28.

Ayrolo, Valentina: «Una nueva lectura de los informes de la misión Muzi: la Santa Sede y la iglesia de las provincias unidas», Boletín del Instituto de Historia

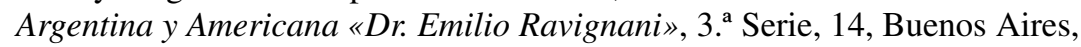
1996, 31-60.

61 Agradezco a uno de los evaluadores de este artículo la observación sobre la presencia de la tradición colonial en estos reclamos autonómicos del patronato. 
Ayrolo, Valentina: Funcionarios de Dios y de la República: Clero y política en la experiencia de las autonomías provinciales, Buenos Aires, Biblos, 2007

Barral, María Elena: «De mediadores componedores a intermediarios banderizos: el clero rural de Buenos Aires y la paz común en las primeras décadas del siglo XIX», Anuario IEHS, 23, Tandil, 2008, 151-174.

Barral, María Elena: «Un salvavidas de plomo. Los curas rurales de Buenos Aires y la reforma eclesiástica de 1822-1823», Prohistoria, 13, Rosario, 2009, 51-68.

Barral, María Elena y Di Stefano, Roberto: «Las 'misiones interiores' en la campaña de Buenos Aires entre dos siglos: de los Borbones a Rosas», Hispania Sacra, LX, Madrid, julio-diciembre 2008, 635-658.

Bragoni, Beatriz y Mata, Sara: «Militarización e identidades políticas en la revolución rioplatense», Anuario de Estudios Americanos, 64-1, Sevilla, enerojunio de 2007, 221-256.

Bransboin, Hernán: «El ejercicio del poder político en la Mendoza 'federal'. 18311852», XI Jornadas Interescuelas/Departamentos de Historia, Tucumán, 2007.

Bruno, Cayetano: Historia de la Iglesia en Argentina, Buenos Aires, Don Bosco, 1966-1976 (12 vols.).

Calvo, Nancy: «Lo sagrado y lo profano. Tolerancia religiosa y ciudadanía política en los orígenes de la república rioplatense», Andes, 15, Salta, 2004.

Castro, Ana: «Primera parte: Desde los orígenes hasta Caseros», en Santos Martínez, Pedro (ed.): Historia de Mendoza, Buenos Aires, Plus Ultra,1979.

Chiaramonte, José Carlos: «La cuestión regional en el proceso de gestación del Estado nacional argentino», Mercaderes del Litoral: Economía y sociedad, Buenos Aires, Fondo de Cultura Económica (FCE), 1991, 21-54.

Chiaramonte, José Carlos: «El federalismo argentino en la primera mitad del siglo XIX», en Carmagnani, Marcello (ed.): Federalismos latinoamericanos: México, Brasil, Argentina, México, FCE, 1993, 81-127.

Chiaramonte, José Carlos: Ciudades, provincias, Estados: Orígenes de la Nación Argentina (1800-1846), Buenos Aires, Ariel, 1997.

Chiaramonte, José Carlos: Nación y Estado en Iberoamérica. El lenguaje político en tiempos de las independencias, Buenos Aires, Sudamericana, 2004.

Di Stefano, Roberto: El púlpito y la plaza. Clero, sociedad y política de la monarquía católica a la república rosista, Buenos Aires, Siglo XXI, 2004.

Di Stefano, Roberto: «El laberinto religioso de Juan Manuel de Rosas», Anuario de Estudios Americanos, 63-1, enero-junio de 2006, 19-50.

Di Stefano, Roberto: «Tolerancia e intolerancia en la historia religiosa de América Latina», conferencia inaugural del Segundo Encontro Nacional do GT História das Religoes e das Religiosidades-ANPUH: Toleranciâ e Intolerancià nas manifestaçoes religiosas, Universidad de São Paulo, Sede de Franca, Brasil, 13 de octubre de 2008. 
Di Stefano, Roberto: «Ut unum sint. La reforma como construcción de la Iglesia (Buenos Aires, 1822-1824)», Rivista di Storia del Cristianesimo, 3, Brescia, 2008, 499-523.

Di Stefano, Roberto y Zanatta, Loris: Historia de la Iglesia argentina, Buenos Aires, Grijalbo-Mondadori, 2000.

García de Saltor, Irene: La construcción del espacio político. Tucumán en la primera mitad del siglo XIX, Tucumán, Universidad Nacional de Tucumán, 2003.

Goldman, Noemí, «Crisis imperial, revolución y guerra (1806-1820)», en Goldman, Noemí (dir.): Revolución, República, Confederación (1806-1852), III de Nueva Historia Argentina, Buenos Aires, Sudamericana, 1998, 21-67.

Halperín Donghi, Tulio: Argentina: de la Revolución de independencia a la Confederación rosista, Buenos Aires, Paidós, 1972.

Hermann, Christian: L'Eglise d'Espagne sous le patronage Royal (1476-1834), Madrid, Casa de Velázquez, 1988.

Legón, Faustino: Doctrina y ejercicio del patronato Nacional, Buenos Aires, 1920.

Lida, Miranda: Dos ciudades y un deán: biografía de Gregorio Funes, Buenos Aires, Eudeba, 2006.

Martínez, Ignacio: «De la monarquía católica a la nación republicana y federal. Soberanía y patronato en el Río de la Plata. 1753-1853», Secuencia, 76, México, enero-abril 2010, 15-38.

Martínez Paz, Enrique: Un episodio eclesiástico en Cuyo: 1824, Córdoba, Instituto de Estudios Americanistas, 1938.

Myers, Jorge: Orden y Virtud. El discurso republicano en el régimen rosista, Buenos Aires, Universidad Nacional de Quilmes, 1995.

Myers, Jorge: «Cuestión de identidad: la búsqueda de los orígenes de la Nación Argentina y sus aporías: a propósito de José Carlos Chiaramonte y su Ciudades, provincias, Estado: Los orígenes de la nación argentina (18001846)», Primas. Revista de Historia Intelectual, 3, Quilmes, 1999, 275-284.

Myers, Jorge: «La revolución en las ideas: la generación romántica de 1837 en la cultura y en la política argentinas», en Goldman, Noemí (dir.): Revolución, República, Confederación (1806-1852), III de Nueva Historia Argentina, Buenos Aires, Sudamericana, 1998, 381-445.

Salvatore, Ricardo: «Fiestas federales: representaciones de la república en el Buenos Aires rosista», Entrepasados, 11, Buenos Aires, 1998, 45-68.

Salvatore, Ricardo: «Consolidación del régimen rosista (1835-1852)», en Goldman, Noemí (dir.): Revolución, República, Confederación (1806-1852), III de Nueva Historia Argentina, Buenos Aires, Sudamericana, 1998, 323-380.

Sierra, Vicente: Historia de la Argentina. VIII: Epoca de Rosas. Primera parte (1829-1840), Buenos Aires, Editorial Científica Argentina, 1969. 
Souto, Nora y Wasserman, Fabio: «Nación», en Goldman, Noemí (ed.), Lenguaje y revolución: Conceptos políticos clave en el Río de la Plata, 1780-1850, Buenos Aires, Prometeo, 2008, 83-98.

Tau Anzoátegui, Víctor: Formación del Estado federal argentino, 1820-1852. El gobierno de Buenos Aires y los asuntos nacionales, Buenos Aires, Perrot, 1996

Ternavasio, Marcela: Historia de la Argentina: 1806-1852, Buenos Aires, Siglo XXI, 2009.

Tonda, Américo: «Rosas, Corrientes y la nunciatura del Brasil», Archivum, 11, Buenos Aires, 1969, 13-34.

Verdaguer, José Anibal: Historia eclesiástica de Cuyo, Milan, Premiata Scuola Tipografica Salesiana, 1932.

Zuretti, Juan Carlos: Nueva historia eclesiástica argentina. Del Concilio de Trento al Vaticano Segundo, Buenos Aires, Itinerarium, 1972. 